\title{
Polyphenol Content and Antioxidant Activity of Stevia and Peppermint as a Result of Organic and Conventional Fertilization
}

\author{
Lina Garcia-Mier, ${ }^{1}$ Adriana E. Meneses-Reyes, ${ }^{2}$ Sandra N. Jimenez-Garcia, ${ }^{3}$ \\ Adan Mercado Luna, ${ }^{2}$ Juan Fernando García Trejo, ${ }^{2}$ Luis M. Contreras-Medina, ${ }^{2}$ \\ and Ana A. Feregrino-Perez $\mathbb{D}^{2}$ \\ ${ }^{1}$ División de Ciencias de la Salud, Universidad del Valle de México, Campus Querétaro. Blvd. Juriquilla No. 1000, \\ Santa Rosa Jáuregui, C.P. 76230, Santiago de Querétaro, Qro, Mexico \\ ${ }^{2}$ Facultad de Ingeniería, Universidad Autónoma de Querétaro, C.U. Cerro de las Campanas S/N, Colonia Las Campanas, \\ C.P. 76010, Santiago de Querétaro, Querétaro, Mexico \\ ${ }^{3}$ Departamento de Enfermería y Obstetricia, División de Ciencias de la Salud e Ingeniería, Campus Celaya-Salvatierra, \\ Universidad de Guanajuato, Av. Mutualismo Esq. Prolongación Río Lerma S/N, Celaya, Guanajuato, C.P. 38060, Mexico \\ Correspondence should be addressed to Ana A. Feregrino-Perez; feregrino.angge@hotmail.com
}

Received 26 November 2020; Revised 16 January 2021; Accepted 20 January 2021; Published 31 January 2021

Academic Editor: Giorgia Liguori

Copyright (c) 2021 Lina Garcia-Mier et al. This is an open access article distributed under the Creative Commons Attribution License, which permits unrestricted use, distribution, and reproduction in any medium, provided the original work is properly cited.

\begin{abstract}
Stevia rebaudiana Bertoni and Mentha piperita are plants that generate interest mainly due to the presence of bioactive compounds in their leaves, such as phenolics. Studies indicate that phenolics have pharmacological and therapeutic properties, including antioxidant activity. Phenolic compounds may be affected by the type of fertilization. For this reason, organic and chemical fertilization were evaluated along with antioxidant activity. Results showed significant differences for total phenols in organic peppermint (62\% higher content). Also, DPPH test displayed differences for peppermint and stevia (572\% and $16 \%$ greater in organic). Organic fertilization may be alternative for producing high added agricultural and commercial products.
\end{abstract}

\section{Introduction}

Dietetics products and natural food ingredient demand has increased over the last years. A lot of interest has emerged on sources of natural antioxidant since many health problems are associated with the action of toxic forms of oxygen responsible for oxidation processes. Antioxidants are capable of inhibiting reactive oxygen species (ROS) [1]. Phenolic compounds may represent approximately $19-23 \%$ of dry peppermint leave weight [2]. It has been reported that phenolics show beneficial health effects due to free radical scavenging properties. Mexican population consumes infusions in a regular manner, and one of the most popular is prepared from peppermint (Mentha piperita). Peppermint leaves contain a wide array of bioactive components (fatty acids, volatile compounds, carotenoids, and phenolic compounds). At the same time, an interest in natural sweeteners has emerged due to the increasing health consciousness and concern related to sugar consumption and the problems related to the safety of some artificial nonnutritive sweeteners [3]. Stevia is an herb of Asteraceae family, which grows wild in South America, such as Paraguay and Brazil. Leaves are the economic part of the plant with a high concentration of steviol glycosides [4]. Stevia rebaudiana Bertoni has been used as a natural sweeter; it is categorized by high concentration of steviol glycosides in its leaves, which are up to 200 to 400 times sweeter than sucrose. In addition to their sweeteners, stevia plants possess other compounds such as terpenes, sterols, volatile acids, vitamins, carotenes, organic acids, polysaccharides, hormones, microelements, and phenolic compounds (tannins and flavonoids) [5].

Particularly important for the antioxidant capacity in stevia and peppermint are phenolic compounds, which are 
secondary metabolites. The promotion of product quality regarding secondary metabolites content may be of high relevance for a commercial expansion of stevia and peppermint. Phenolic compounds are involved in various plant processes such as growth and reproduction and are also synthesized as a defense mechanism to various stresses; therefore, their production can be enhanced by different conditions, among them, type of fertilization. Nowadays, consumers are more concerned of possible exposure to agrochemicals. Organic agricultural practices do not allow the use of chemical compounds for crop nutrition, synthetic compounds for pest, disease, and weed control. Many have suggested that the use of organic fertilizers is an essential source of nutrients for sustainable agriculture and in addition to cover the physiological requirements of crops, favoring the development of high-quality crops [6]. Due to a plethora of implications, among them, health benefits and the use of environmental friendly agriculture practices [7], the aim of this study was investigating the effect of organic and chemical (conventional) fertilization on the content of bioactive compounds in S. rebaudiana and M. piperita. The work is focused on the analysis of antioxidant capacity, phenolic compounds, and steviosides levels in those materials, to assess differences between both types of fertilization.

\section{Materials and Methods}

2.1. Plant Material. Conventional peppermint and stevia plants were obtained from a local supplier. The plants belonged to the same batch. Organic stevia plants were got from a commercial greenhouse with organic care located at San José Iturbide, Guanajuato, México. Organic peppermint was grown at the Universidad Autónoma de Querétaro, Amazcala campus. Leaves were collected and dried at $45^{\circ} \mathrm{C}$ for $24 \mathrm{~h}$ (Fisher Scientific, 650D, USA). Next, they were milled in a grinder (Krups GX4100, México).

2.2. Extract Preparation. Extraction for phenolics and antioxidant determinations were performed by placing $1 \mathrm{~g}$ (PRACTUM 224-1S; Sartorius, Göttingen, Germany) of fresh sample in a $50 \mathrm{~mL}$ tube and mixed with $10 \mathrm{ml}$ of methanol. The tubes were protected from light and shaken at $200 \mathrm{rpm}$ (Orbit 1000 model S2030-1000; Labnet, Woodbridge, NJ, USA) for $24 \mathrm{~h}$ at $25^{\circ} \mathrm{C}$. After incubation, the samples were centrifuged (Sorvall Biofuge Primo $R$ model 75005448; Thermo Scientific, Osterode, Germany) at $6,793 \times g$ for $10 \mathrm{~min}$. Aliquots of the supernatant were taken for the assays. We followed the methods of Garcia-Mier, Jimenez-Garcia [8].

2.3. Quantification of Condensed Tannins. Condensed tannins expressed as milligrams of $(+)$-catechin equivalents per gram of dry sample were quantified according to the next procedure proposed by Garcia-Mier, Jimenez-Garcia [8]. Briefly, $200 \mu \mathrm{l}$ of vanillin reagent (1\% vanillin, $8 \% \mathrm{HCl}$ in methanol) was added to $50 \mu \mathrm{l}$ of methanolic extract and placed in a 96-well plate; each sample was tested in triplicate. Condensed tannins were quantified at $492 \mathrm{~nm}$ in a microplate reader (Multiskan Go model 51119300; Thermo Scientific, Vantaa, Finland) using (+)-catechin (up to $0.1 \mathrm{mg} \cdot \mathrm{mL}^{-1}$ ) as a reference standard. A blank sample was prepared by subjecting the original extract to the same conditions of reaction without the vanillin reagent.

2.4. Quantification of Flavonoids. Briefly, the method for the determination of flavonoids content was performed according to Garcia-Mier, Jimenez-Garcia [8]. It consisted of mixing $50 \mu \mathrm{l}$ of the methanolic extract with $180 \mu \mathrm{l}$ of distilled water and $20 \mu \mathrm{l}$ of a solution 2-aminoethyldiphenylborate $1 \%$ in a 96 -well plate. The absorbance of the solution was monitored at $404 \mathrm{~nm}$ with a microplate reader (Multiskan Go model 51119300; Thermo Scientific, Vantaa, Finland). A rutin standard was prepared in methanol. Extract absorption was compared with that of a rutin standard curve (up to $2 \mu \mathrm{g} \cdot \mathrm{ml}^{-1}$ ). Flavonoid content was expressed as $\mathrm{mg}$ of rutin equivalent per gram of dry sample.

2.5. Quantification of TotalPhenols. Total phenols (expressed as $\mathrm{mg}$ of gallic acid equivalent per gram of dry sample) were determined by the Folin-Ciocalteu method with modifications. To $40 \mu \mathrm{L}$ of extract were added $460 \mu \mathrm{L}$ of distilled water, $250 \mu \mathrm{L}$ of Folin Ciocalteau reagent, and $1250 \mu \mathrm{L}$ of $20 \%$ sodium carbonate solution. After 2 hours in the dark, samples were read at $750 \mathrm{~nm}$ in a UV/Vis spectrophotometer (Genesys 10S UV-Vis, Themo Fischer Scientific, USA). Gallic acid was used for the calibration curve [9].

2.6. Antioxidant Activity by 1,1-Diphenyl-2-picrylhydrazyl Radical (DPPH) Inhibition Assay. Radical scavenging activity (RSA) was determined using stable radical DPPH method. The assay was performed following the next procedure. All reactions were conducted in 96-well microplates. Aliquot $(20 \mu \mathrm{L})$ of methanolic extracts was mixed with $100 \mu \mathrm{M}$ of DPPH $(200 \mu \mathrm{l})$ in methanol. It was used a control and a blank. After 30-minute incubation at ambient temperature in darkness, absorbance was recorded at $515 \mathrm{~nm}$ in a microplate reader (Multiskan Go model 51119300; Thermo Scientific, Vantaa, Finland). It was prepared as a calibration curve with Trolox. The antioxidant activity was expressed as percent of inhibition [8].

2.7. Antioxidant Activity by 2,2'-Azino-bis(3-ethylbenzothiazoline-6-sulphonic Acid) (ABTS) Inhibition Assay. The radical cation was prepared by mixing $7 \mathrm{mM}$ ABTS stock solution with $140 \mathrm{mM}$ potassium persulfate $(1 / 1, \mathrm{v} / \mathrm{v})$ and leaving the mixture for $12 \mathrm{~h}$ until reaction was completed and the absorbance was stable. The $\mathrm{ABTS}^{+}$solution was diluted with ethanol to an absorbance of $0.700 \pm 0.05 \mathrm{~nm}$ at $730 \mathrm{~nm}$ for measurement. The photometric assay was conducted on $0.9 \mathrm{~mL}$ of ABTS solution and $0.1 \mathrm{~mL}$ of extract and mixed for 45 seconds, and measurements were taken at $730 \mathrm{~nm}$ after 15 minutes. The antioxidant activity of the sample was calculated by determining the decrease in absorbance. Trolox was used as standard substance. This assay was based on the ability of different substances to scavenge 
radicals. The antioxidant activity was expressed as percent of inhibition [10].

2.8. HPLC Analysis. For extraction, purification, and quantification of stevia extracts, the methodology used was proposed by Mondal, Majumdar [11]. It consisted of S. rebaudiana freeze-dried leaves $(1 \mathrm{~g})$ that were mixed with $10 \mathrm{~mL}$ of a mobile phase (acetonitrile: water $80: 20$ ) for 20 minutes. Rebaudioside A was identified and quantified by the high-pressure liquid chromatography method (HPLC, Hewlett Packard 1100 model), in which $20 \mu \mathrm{L}$ was taken and was injected into the chromatography equipment. The used column was Zorbax Carbohydrate with a flow of $0.1 \mathrm{~mL} /$ $\min$.

2.9. Statistical Analysis. Data were subjected to analysis of variance (ANOVA) followed by Student's t-test (with $P \leq 0.05$ ) by JMP (SAS Institute Inc., Cary, NC, USA).

\section{Results and Discussion}

3.1. Phenolic Compounds. Phenolic compounds, flavonoids, and condensed tannins as well as antioxidant activity were analyzed in stevia and peppermint by spectrophotometric methods after the application of organic and conventional fertilization. A number of reports indicate that these compounds are involved in the prevention of non-transmissible chronic diseases by means of their antioxidant activity $[12,13]$. The total phenol, flavonoid, and tannin content for stevia and peppermint are shown in Tables 1 and 2. Results indicate significant differences between organic and conventional fertilization in peppermint for total phenolics but not for flavonoids and condensed tannins; these variables do not display significant differences in stevia; nevertheless, it is relevant to mention that organic stevia has 33\% more total phenols than the conventional one. In the high total phenolic content in peppermint, other phenolics may be implicated apart from flavonoids and condensed tannins such as phenolic acids, and caffeic acid derivatives were the most abundant phenolic compounds in stevia [14]; also, caffeic acid was the most abundant phenolic acid in peppermint [15]; hydroxycinnamate derivatives have been identified and quantified in stevia methanolic extracts $[2,16]$. Various authors have stated that the use of organic fertilizer enhances the amount of secondary metabolites such as phenolic as well the antioxidant activity in crops $[17,18]$. The amount of stevia phenolic compounds found in this study is considerably lower than those reported by other studies (e.g., total phenol: $80.13 \mathrm{mg}$ gallic acid/g extract and total flavonoids: $111.16 \mathrm{mg}$ quercetin/g extract) $[5,19,20]$. The same behavior occurs for peppermint, where total phenolic and total flavonoid in peppermint leaves were $360.04 \pm 0.285$ and $421.96 \pm 0.25 \mathrm{mg} 100 \mathrm{~g}^{-1}$, respectively [21]. According to Gupta et al. [22], tannin detected content in stevia leaves is $5.68 \mathrm{mg} 100 \mathrm{~g}^{-1}$ what is higher than the amount found in this work. Sujana et al. [23] reported $2 \mathrm{mg} \cdot \mathrm{g}^{-1}$ of tannins; this value is higher than the one found in this research. Higher levels of total phenolic content were consistently found in organic and sustainable marionberries, strawberries, and corn as compared to those produced by conventional agricultural practices [24]. According to the study of Faller and Fialho [25] made on fruits and vegetables, organic agriculture results in food products with similar or marginally higher polyphenol content and antioxidant capacity. The perception among consumers is that organic cultivars possess a higher nutritional quality than conventional; nevertheless, it is not easy to estimate compositional differences due to agricultural practices because of the vast number of variables such as crop, irrigation patterns, weather variations, handling, etc. Post-harvest management and also laboratory extraction techniques may be implicated in these differences [6].

3.2. Antioxidant Activity. Antioxidant capacity was determined in extracts from leaves of $S$. rebaudiana Bertoni and M. piperita. This activity was characterized by two different assays, consisting of measuring the ability to scavenge the DPPH radical. Results obtained are shown in Tables 3 and 4 for stevia and peppermint, respectively. A different behavior between these two tests can be observed. In the ABTS test, no significant differences were observed. However, DPPH test displayed significant differences for both plants. Stevia presented $0.880 \pm 0.009$ and $0.827 \pm 0.16 \mathrm{mg}$ Trolox equivalent $g$ of extract ${ }^{-1}$ for organic and chemical fertilization, respectively. Peppermint has $0.889 \pm 0.014$ and $0.558 \pm 0.028 \mathrm{mg}$ Trolox equivalent $\mathrm{g}$ of extract ${ }^{-1}$ for organic and conventional fertilization, respectively. These results are lower than those presented in other studies [13]. This may be related to the lower amount of phenolic compounds founds in the material tested. Yildiz-Ozturk et al. [19] found DPPH radical scavenging activities of around $90 \%$ which are higher than the ones found; nevertheless, Singh et al. [26] reported radical scavenging activities (\%) that ranged between $47.1 \%$ and $82.4 \%$ for leaf and flower, respectively. Both assays are classified into the group of single electron transfer based methods, which accounts for the similarity of results reported in many occasions. However, it must be considered that the conditions in which the tests are performed are different, so they must be considered complementary [27]. Total phenolic content correlates positively with antioxidant activity. Other studies have found the same relation. It is stated that antioxidant capacity characterizing stevia leaves is mainly attributable to the presence phenolic compounds, such as flavonoids [2] and steviosides [28]; Barroso et al. [14] stated the total flavonoid content was less strongly correlated with the antioxidant activity in comparison with the total phenolic acids, due to its higher concentration present in stevia. . The phenolic compounds present in the herbs and spices have been reported to show natural antioxidant activity and are applied as food preservatives. The predominant mode of antioxidant activity of phenolic compounds is believed to be a radical scavenging via hydrogen donation [5].

Organic fertilization may enhance some bioactive compounds that correlate with antioxidant activity in plants; however, more research is needed to ensure getting high 
TABLE 1: Total phenolics, flavonoids, and condensed tannins in stevia ${ }^{a}$.

\begin{tabular}{lcccc}
\hline Fertilization & Plant & Total phenolics $^{\mathrm{b}}$ & Flavonoids $^{\mathrm{c}}$ & Condensed tannins $^{\mathrm{d}}$ \\
\hline Organic & Stevia & $0.948 \pm 0.157^{\mathrm{a}}$ & $0.165 \pm 0.030^{\mathrm{a}}$ & $0.006 \pm 0.001^{\mathrm{a}}$ \\
Conventional & Stevia & $0.708 \pm 0.089^{\mathrm{a}}$ & $0.186 \pm 0.088^{\mathrm{a}}$ & $0.006 \pm 0.002^{\mathrm{a}}$ \\
\hline
\end{tabular}

${ }^{\mathrm{a}} \mathrm{Each}$ value is the mean of three replicates \pm standard error. Different letters in each column express significant difference $P \leq 0.05$ by Student's t-test. ${ }^{\mathrm{b}} \mathrm{mg}$ of gallic acid equivalent/g of dry sample. ${ }^{c} \mathrm{mg}$ equivalent of rutin/g of dry sample. ${ }^{\mathrm{d}} \mathrm{mg}$ of $(+)$ catequine equivalent/g dry sample.

TABLE 2: Total phenolics, flavonoids, and condensed tannins in peppermint ${ }^{\mathrm{a}}$.

\begin{tabular}{lcccc}
\hline Fertilization & Plant & Total phenolics $^{\mathrm{b}}$ & Flavonoids $^{\mathrm{c}}$ & Condensed tannins $^{\mathrm{d}}$ \\
\hline Organic & Peppermint & $0.905 \pm 0.055^{\mathrm{a}}$ & $0.112 \pm 0.006^{\mathrm{a}}$ & $0.001 \pm 0.000^{\mathrm{a}}$ \\
Conventional & Peppermint & $0.558 \pm 0.047^{\mathrm{b}}$ & $0.379 \pm 0.037^{\mathrm{b}}$ & $0.017 \pm 0.005^{\mathrm{b}}$ \\
\hline
\end{tabular}

${ }^{a}$ Each value is the mean of three replicates \pm standard error. Different letters in each column express significant difference $P \leq 0.05$ by Student's t-test. ${ }^{b} \mathrm{mg}$ of gallic acid equivalents/g of dry sample. ${ }^{c} \mathrm{mg}$ equivalent of rutin/g of dry sample. ${ }^{\mathrm{d}} \mathrm{mg}$ of $(+)$ catequine equivalent/g dry sample.

TABLE 3: Radical scavenging activity of stevia as a result of type of fertilization ${ }^{\mathrm{a}}$.

\begin{tabular}{lccc}
\hline \multirow{2}{*}{ Fertilization } & Plant & ABTS & DPPH inhibition \\
\hline Organic & Stevia & $92.847 \pm 2.394^{\mathrm{a}}$ & $72.780 \pm 1.817^{\mathrm{a}}$ \\
Conventional & Stevia & $94.526 \pm 0.077^{\mathrm{a}}$ & $62.681 \pm 3.076^{\mathrm{b}}$ \\
\hline a Each value is the mean of three replicates \pm standard error. Different letters \\
in each column express significant difference $P \leq 0.05$ by Student's $t$-test.
\end{tabular}

TABLE 4: Radical scavenging activity of peppermint as a result of type of fertilization ${ }^{\mathrm{a}}$.

\begin{tabular}{|c|c|c|c|}
\hline Fertilization & Plant & \multicolumn{2}{|c|}{ \% inhibition } \\
\hline Organic & Peppermint & $93.783 \pm 0.210^{\mathrm{a}}$ & $74.474 \pm 2.801^{\mathrm{a}}$ \\
\hline Conventional & Peppermint & $93.330 \pm 0.406^{\mathrm{a}}$ & $11.815 \pm 5.336^{b}$ \\
\hline
\end{tabular}

${ }^{\mathrm{a}}$ Each value is the mean of three replicates \pm standard error. Different letters in each column express significant difference $P \leq 0.05$ by Student's $t$-test.

added value agricultural products and nutraceutical products. In some cases, the strategy is not just organic or conventional but integrative, as the one exposed for peppermint where the application of chemical fertilizers with nano fertilizers can be an alternative to improve the qualiquantitative characteristics of peppermint [29]. More foods must be evaluated to solve the controversy of whether organic foods have a nutritional and/or sensory advantage when compared to their conventionally produced counterparts.

Due to their amount of steviol glycosides, which are of great medicinal and nutraceutical importance worldwide, two different varieties of stevia (Morita and Eriete) were evaluated in their amount of glycosides (stevioside, rebaudioside $\mathrm{A}$, and rebaudioside $\mathrm{C}$ ) under organic and conventional fertilization. For organic fertilization, in Morita, the stevioside, rebaudioside $\mathrm{A}$, and rebaudioside $\mathrm{C}$ content expressed as $\mathrm{mg} / \mathrm{g}$ of dry matter was $9.582,1.184$, and 7.496, respectively. For Eriete, it was 1.160, 24.719, and 5.748, respectively. For Morita cultivated under conventional fertilization, steviosides were not detected and rebaudioside A was found in an amount of $14.877 \mathrm{mg} / \mathrm{g}$ of dry matter and rebaudioside $C$ in 5.893. Eriete under this same condition presented $25.710 \mathrm{mg} / \mathrm{g}$ of dry matter for rebaudioside A and
$4.891 \mathrm{mg} / \mathrm{g}$ of dry matter for rebaudioside C. No differences in the steviol glycoside content were found between varieties or fertilization. Díaz-Gutiérrez et al. [30] found concentration of rebaudioside $\mathrm{C}$ and stevioside increased under organo-mineral fertilizer (compost from poultry manure with inorganic salts) under greenhouse conditions. These authors found that nutrients as nitrogen, calcium, magnesium, and sulfur presented a significant correlation with the production of steviol glycosides. The implication of nitrogen fertilization in the production of steviol glycosides and other stevia bioactives has been also stated by other authors $[14,28]$, implying that adequate $\mathrm{N}$ rate is important to significantly increase and optimize the bioactive compound levels in stevia; however, it was stated by Barbet-Massin et al. [31] that steviol concentration in the leaf decreased with increasing nitrogen concentration; then, the implication of nitrogen in the development of steviol glycosides needs further evaluation since it also implies that an $\mathrm{N}$ deficit could be switching between the production of steviol glycoside and the synthesis of key isoprenoids, such as gibberellins, chlorophylls, and carotenoids.

It is identified that, among steviol glycosides, stevioside and rebaudioside A are present in the highest concentrations. Stevioside is 300 times sweeter than sucrose; it has a slight licorice flavor and a bitter aftertaste. In contrast, rebaudioside A lacks the bitter aftertaste and is 250 up to 400 times sweeter than sucrose [31]; for this reason, the rebaudioside $\mathrm{A} /$ stevioside ratio is considered a parameter to measure the quality of stevia extract [32]. For Morita cultivated under organic condition, rebaudioside $\mathrm{A} /$ stevioside ratio was of 0.12, whereas for Eriete it was 21.31. In cultivars grown in conventional manner, no stevioside was detected. The results for Eriete are relevant since it will develop a better taste in steviol glycoside products. It is relevant to mention that the ratio reported here is higher than the one reported in a study where mannitol, an $\mathrm{NaCl}$ stress, was evaluated (0.75-1.53).

Results obtained in the present investigation suggest that stevia and peppermint grown under organic conditions display higher levels of polyphenols and antioxidant activity; nonetheless, additional research must be done to confirm possible differences between conventional and organic stevia 
and peppermint in order to provide better guidance to agricultures and consumers.

\section{Data Availability}

The data are available from the corresponding author upon request.

\section{Conflicts of Interest}

The authors declare that there are no conflicts of interest regarding the publication of this paper.

\section{Acknowledgments}

Special thanks are extended to FOFIUAQ. The authors thank FOFIUAQ for their support of this work.

\section{References}

[1] M. K. Roy, M. Takenaka, S. Isobe, and T. Tsushida, "Antioxidant potential, anti-proliferative activities, and phenolic content in water-soluble fractions of some commonly consumed vegetables: effects of thermal treatment," Food Chemistry, vol. 103, no. 1, pp. 106-114, 2007.

[2] M. G. Figueroa Pérez, N. E. Rocha-Guzmán, E. MercadoSilva, G. Loarca-Piña, and R. Reynoso-Camacho, "Effect of chemical elicitors on peppermint (Mentha piperita) plants and their impact on the metabolite profile and antioxidant capacity of resulting infusions," Food Chemistry, vol. 156, pp. 273-278, 2014.

[3] K. Amin, S. Ozgen, and Z. Selamoglu, "Stevia rebaudiana: a potential boon for human health," SM Journal of Medicinal Plant Studies, vol. 1, p. 1005, 2017.

[4] M. Reis, L. Coelho, G. Santos, U. Kienle, and J. Beltrão, "Yield response of stevia (Stevia rebaudiana Bertoni) to the salinity of irrigation water," Agricultural Water Management, vol. 152, pp. 217-221, 2015.

[5] J. C. Ruiz Ruiz, Y. B. Moguel Ordoñez, M. Á. Basto, and M. R. Segura Campos, "Antioxidant capacity of leaf extracts from two Stevia rebaudiana Bertoni varieties adapted to cultivation in Mexico," Nutricion Hospitalaria, vol. 31, 2015.

[6] A. Moreno-Reséndez, R. Parcero-Solano, J. L. Reyes-Carrillo et al., "Organic manures improved the phenolic content, antioxidant capacity and soluble solids in pepper," Food and Nutrition Sciences, vol. 07, no. 14, p. 1401, 2016.

[7] K. Umesha, G. R. Smitha, B. S. Sreeramu, and A. A. Waman, "Organic manures and bio-fertilizers effectively improve yield and quality of stevia (Stevia rebaudiana)," Journal of Applied Horticulture, vol. 13, no. 02, pp. 157-162, 2011.

[8] L. Garcia-Mier, S. N. Jimenez-Garcia, R. G. GuevaraGonzález, A. A. Feregrino-Perez, L. M. Contreras-Medina, and I. Torres-Pacheco, "Elicitor mixtures significantly increase bioactive compounds, antioxidant activity, and quality parameters in sweet bell pepper," Journal of Chemistry, vol. 2015, Article ID 269296, 2015.

[9] V. Dewanto, X. Wu, K. K. Adom, and R. H. Liu, “Thermal processing enhances the nutritional value of tomatoes by increasing total antioxidant activity," Journal of Agricultural and Food Chemistry, vol. 50, no. 10, pp. 3010-3014, 2002.

[10] M. Oh and K. Yoon, "Comparison of the biological activity of crude polysaccharide fractions obtained from Cedrela sinensis using different extraction methods," Polish Journal of Food and Nutrition Sciences, vol. 68, no. 4, pp. 327-334, 2018.

[11] S. Mondal, G. Majumdar, and S. De, "Clarifications of stevia extract using cross flow ultrafiltration and concentration by nanofiltration," Separation and Purification Technology, vol. 89, pp. 125-134, 2012.

[12] A. Carrera-Lanestosa, Y. Moguel-Ordóñez, and M. SeguraCampos, "Stevia rebaudiana Bertoni: a natural alternative for treating diseases associated with metabolic syndrome," Journal of Medicinal Food, vol. 20, pp. 933-943, 2017.

[13] M. J. Álvarez-Robles, A. López-Orenes, M. A. Ferrer, and A. A. Calderón, "Methanol elicits the accumulation of bioactive steviol glycosides and phenolics in Stevia rebaudiana shoot cultures," Industrial Crops and Products, vol. 87, pp. 273-279, 2016.

[14] M. R. Barroso, N. Martins, L. Barros et al., "Assessment of the nitrogen fertilization effect on bioactive compounds of frozen fresh and dried samples of Stevia rebaudiana Bertoni," Food Chemistry, vol. 243, pp. 208-213, 2018.

[15] J. Lv, H. Huang, L. Yu et al., "Phenolic composition and nutraceutical properties of organic and conventional cinnamon and peppermint," Food Chemistry, vol. 132, no. 3, pp. 1442-1450, 2012.

[16] M. Molina-Calle, F. Priego-Capote, and M. D. Luque de Castro, "Characterization of Stevia leaves by LC-QTOF MS/ MS analysis of polar and non-polar extracts," Food Chemistry, vol. 219, pp. 329-338, 2017.

[17] N. F. Omar, S. A. Hassan, U. K. Yusoff, N. A. P. Abdullah, P. E. M. Wahab, and U. R. Sinniah, "Phenolics, flavonoids, antioxidant activity and cyanogenic glycosides of organic and mineral-base fertilized cassava tubers," Molecules, vol. 17, no. 3, pp. 2378-2387, 2012.

[18] M. Ibrahim, H. Jaafar, E. Karimi, and A. Ghasemzadeh, "Impact of organic and inorganic fertilizers application on the phytochemical and antioxidant activity of Kacip Fatimah (Labisia pumila Benth)," Molecules, vol. 18, no. 9, pp. 10973-10988, 2013.

[19] E. Yildiz-Ozturk, A. Nalbantsoy, O. Tag, and O. Yesil-Celiktas, "A comparative study on extraction processes of Stevia rebaudiana leaves with emphasis on antioxidant, cytotoxic and nitric oxide inhibition activities," Industrial Crops and Products, vol. 77, pp. 961-971, 2015.

[20] I.-S. Kim, M. Yang, O.-H. Lee, and S.-N. Kang, "The antioxidant activity and the bioactive compound content of Stevia rebaudiana water extracts," LWT-Food Science and Technology, vol. 44, no. 5, pp. 1328-1332, 2011.

[21] A. Dyab, A. Aly, and H. Matuk, "Enhancement and evaluation of peppermint (Mentha piperita L.) beverage," 2015.

[22] E. Gupta, S. Purwar, A. Singh, S. Sundaram, and G. Rai, "Evaluation of nutritional, anti-nutritional and bioactive compounds in juice and powder of stevia rebaudiana," Indian Journal of Natural Sciences, vol. 5, no. 28, 2015.

[23] P. Sujana, T. M. Sridhar, P. Josthna, and C. V. Naidu, “Antibacterial activity and phytochemical analysis of," American Journal of Plant Sciences, vol. 4, p. 77, 2013.

[24] D. K. Asami, Y.-J. Hong, D. M. Barrett, and A. E. Mitchell, "Comparison of the total phenolic and ascorbic acid content of freeze-dried and air-dried marionberry, strawberry, and corn grown using conventional, organic, and sustainable agricultural practices," Journal of Agricultural and Food Chemistry, vol. 51, pp. 1237-1241, 2003.

[25] A. Faller and E. Fialho, "Polyphenol content and antioxidant capacity in organic and conventional plant foods," Journal of Food Composition and Analysis, vol. 23, pp. 561-568, 2010. 
[26] S. Singh, V. Garg, D. Yadav, M. N. Beg, and N. Sharma, "In vitro antioxidative and antibacterial activities of various parts of Stevia rebaudiana (Bertoni)," International Journal of Pharmacy and Pharmaceutical Sciences, vol. 4, pp. 468-473, 2012.

[27] J.-K. Moon and T. Shibamoto, "Antioxidant assays for plant and food components," Journal of Agricultural and Food Chemistry, vol. 57, pp. 1655-1666, 2009.

[28] S. Tavarini, C. Sgherri, A. M. Ranieri, and L. G. Angelini, "Effect of nitrogen fertilization and harvest time on steviol glycosides, flavonoid composition, and antioxidant properties in Stevia rebaudiana Bertoni," Journal of Agricultural and Food Chemistry, vol. 63, pp. 7041-7050, 2015.

[29] A. Ostadi, A. Javanmard, M. A. Machiani, M. R. Morshedloo, M. Nouraein, and F. Rasouli, "Effect of different fertilizer sources and harvesting time on the growth characteristics, nutrient uptakes, essential oil productivity and composition of Mentha x piperita L," Industrial Crops and Products, vol. 148, Article ID 112290, 2020.

[30] C. Díaz-Gutiérrez, A. Hurtado, A. Ortíz, C. Poschenrieder, C. Arroyave, and C. Peláez, "Increase in steviol glycosides production from Stevia rebaudiana Bertoni under organomineral fertilization," Industrial Crops and Products, vol. 147, Article ID 112220, 2020.

[31] C. Barbet-Massin, S. Giuliano, L. Alletto, J. Daydé, and M. Berger, "Nitrogen limitation alters biomass production but enhances steviol glycoside concentration in Stevia rebaudiana Bertoni," PLoS One, vol. 10, no. 7, Article ID e0133067, 2015.

[32] S. Hajihashemi and J. M. Geuns, "Steviol glycosides correlation to genes transcription revealed in gibberellin and paclobutrazol-treated Stevia rebaudiana," Journal of Plant Biochemistry and Biotechnology, vol. 26, pp. 387-394, 2017. 